\title{
Development of High-specificity Antibodies against Renal Urate Transporters Using Genetic Immunization
}

\author{
Guoshuang Xu, Xiangmei Chen*, Di Wu, Suozhu Shi, Jianzhong Wang, Rui Ding, \\ Quan Hong, Zhe Feng, Shupeng Lin and Yang Lu \\ Department of Nephrology, Institute of Nephrology \& Key Lab of PLA, General Hospital of PLA, Beijing 100853, P. R. China
}

Received 6 May 2006, Accepted 20 July 2006

\begin{abstract}
Recently three proteins, playing central roles in the bidirectional transport of urate in renal proximal tubules, were identified: two members of the organic anion transporter (OAT) family, OAT1 and OAT3, and a protein that designated renal urate-anion exchanger (URAT1). Antibodies against these transporters are very important for investigating their expressions and functions. With the cytokine gene as a molecular adjuvant, genetic immunization-based antibody production offers several advantages including high specificity and high recognition to the native protein compared with current methods. We fused high antigenicity fragments of the three transporters to the plasmids pBQAP-TT containing T-cell epitopes and flanking regions from tetanus toxin, respectively. Gene gun immunization with these recombinant plasmids and two other adjuvant plasmids, which express granulocyte/ macrophage colony-stimulating factor and FMS-like tyrosine kinase 3 ligand, induced high level immunoglobulin $\mathbf{G}$ antibodies, respectively. The native corresponding proteins of URAT1, OAT1 and OAT3, in human kidney can be recognized by their specific antibodies, respectively, with Western blot analysis and immunohistochemistry. Besides, URAT1 expression in Xenopus oocytes can also be recognized by its corresponding antibody with immuno-fluorescence. The successful production of the antibodies has provided an important tool for the study of UA transporters.
\end{abstract}

Keywords: Antibodies, Genetic immunization, Kidney, Mice, Transporters, Uric acid/urate

\footnotetext{
*To whom correspondence should be addressed.

Tel: 86-10-66937011; Fax: 86-10-68130297

E-mail:xmchen@public.bta.net.cn
}

A comprehensive understanding of the renal handling of uric acid/urate (UA) has been complicated by several factors (Rafey et al., 2003). Not only does UA transport vary among species, but also there exists bidirectional transport of UA across renal tubular cells (Lang, Greger, Deetjen, 1972; Schali, Roch-Ramel, 1981; Capasso et al., 2005). Three complementary DNAs have recently been cloned whose expressed proteins transport UA. One of these proteins, a urate-anion exchanger (URAT1), has been localized to the apical membrane of proximal tubular cells (Enomoto et al., 2002). The other two UA transport proteins, OAT1 and OAT3, members of the organic anion transporter family, have been localized to the basolateral membrane of proximal tubular cells (Hosoyamada et al., 1999; Cha et al., 2001). URAT1 is responsible for luminal reabsorption of UA (Enomoto et al., 2002; Hosoyamada et al., 2004), while OAT1 and OAT3 may be responsible for uptake of UA from the peritubular space, the first step in the process of UA secretion (Hediger et al., 2005; Mount, 2005).

Antibodies against these transporters will help to identify the molecular basis of UA transport in physiological and pathological status. Although several studies reported generation of polyclonal antibodies against OAT1 and OAT3 by immunization with a keyhole limpet hemocyanin-conjugated synthesized peptide (Hosoyamada et al., 1999; Cha et al., 2001), their results were different from each other especially in the identification of these antibodies by Western blot (Kojima et al., 2002). Antibody against URAT1 was firstly generated by Enomoto and colleagues (Enomoto et al., 2002), but their Western blotting analysis indicated that this antibody recognized a band of relative molecular mass $40 \mathrm{kD}$ instead of $59 \mathrm{kD}$, the deduced hURAT1 molecular mass. Thus, it's necessary to generate more specific antibodies against these UA transporters.

Current methods for producing antibodies are not only a laboring work but also a rate-limiting step (Kodadek, 2001). Genetic immunization-based antibody production offers several advantages including high throughput and high specificity 
(Babiuk, van, Babiuk, 1999). Moreover, antibodies produced from genetically immunized animals are more sensitive to recognize the native protein (Tang, DeVit, Johnston, 1992). Unfortunately this method has received relatively little attention because of its variable success (Babiuk, van, Babiuk, 1999). To produce antibodies of high throughput and high specificity by genetic immunization, many adjuvants include tetanus toxin, cytokines (IL-4, IL-12,GM-CSF) (Trinchieri, 1998; Ghochikyan et al., 2003; Barouch, Letvin, Seder, 2004)and the FMS-like tyrosine kinase 3 ligand (Flt3L) (Baca-Estrada et al., 2002) were used together with antigen to induces antigen-specific humoral and cellular immune responses. Recently-Chambers RS and colleagues (Chambers and Johnston, 2003) established a new system for producing antibodies using genetic immunization. To overcome humoral tolerance, exogenous T-cell epitopes were fused to the antigen. With plasmids encoding the cytokines GM-CSF and Flt3L as molecular adjuvants, their system, which was tested by immunization mice with over 130 kinds of antigens, has shown a high success rate of $84 \%$.

Transporter has many membrane-spanning domains, and few continuous antigen fragments could be used as an antigen for immunization. The antigen fragments of these proteins always hardly could be overexpressed in E. coli (Chambers and Johnston, 2003). Therefore, it is difficult in inducing antibodies against membrane proteins by protein immunization. Here we used this new system of genetic immunization to observe whether it can induce high-specific and high-level antibodies against the three UA transporters. The antibodies titer was tested by ELISA. Their specificity was detected by Western blot analysis and immunohistochemistry to observe whether they can recognize native proteins of human kidney, and by immunofluorescence to observe whether they can recognize the expression products in vitro.

\section{Materials and Methods}

Mice. Six-week-old female NIH mice were purchased from Academy of Military Medical Sciences of PLA. All animals were housed in the Center of Experimental Animal, Chinese General Hospital of PLA.

DNA constructs. The genetic immunization plasmids pBQAP-TT that contained either the P2 and P30 'universal' T-cell epitopes and flanking regions from tetanus toxin (50 residues), were gifted by Dr. Ross Chambers, Center for Biomedical Inventions, Department of Internal Medicine, University of Texas-Southwestern Medical Center. Antigen (AESARWLLTTGRLDWGLQELWRVAAINGK GAVQDTLTPEVLLSAMREELSMGQPPASLGTLLRMPGLRFR for hURAT1, ESARWHSSSGRLDLTLRALQRVARINGKREEG AKLSMEV LRASLQKELTMGKGQASAMELLRCPTLRHL for hOAT1, SWWTPESIRWWSCLEVLEGPEDTPAGGCLQWQEE GERLSLEELKLNLQKEISLAKAKYTASDLFRIPIGAPHDLLL for hOAT3) genes were designed by analysing with Accelrys (Accelrys Inc.) software, amplified by RT-PCR from total RNA of human kidney and rescued with the TA cloning pCR2.1 plasmid kit then subcloned into pBQAP-TT with Bcl I and Xma I sites (Chambers and Johnston, 2003).

Expression of antigens and its purification. Using the same method, antigen genes were cloned into pGEM-5X-1 with EcoR I and Xho I sites and were transformed into E. coli BL21, cultured and induced with IPTG to obtain the fusion proteins with glutathione S-transferase (GST). These fusion proteins were purified with Glutathione-Sepharose 4B affinity chromatography (PIERCE Biotech), then digested with factor Xa protease (Promega) and treated with Glutathione-Sepharose 4B affinity chromatography to obtain purified antigens (Sun et al., 2005).

Genetic immunization. Plasmids were delivered using the Helios gene gun (Bio-Rad) as described (Chambers, Johnston, 2003; Ghochikyan et al., 2003). Bullets were prepared according to the manufacturer's instruction with a mixture of plasmids encoding the antigen and plasmids encoding mouse GM-CSF and mouse Flt3L (pBQAP-TT : pCMV-GM-CSF : pCMV-Flt3L = $2: 1: 1$ ). Each bullet contained about $2 \mu \mathrm{g}$ of DNA. Mice were anesthetized with pentobarbitone sodium (100 mg/kg intraperitoneally) and shot in each ear using 400 p.s.i. to fire the gene gun. Mice were immunized and boosted by the same method triweekly. Blood was collected by tail bleeds 2 weeks after the fourth boost and allowed to stand for $2 \mathrm{~h}$ at $24^{\circ} \mathrm{C}$, after which the sera were collected by centrifugation.

Enzyme-linked immunosorbent assay. Antibodies against UA transporters have been detected by Enzyme-linked immunosorbent assay (ELISA) as described (Cribbs et al., 2003; Ghochikyan et al., 2003). Briefly, wells of 96-well plates (NUNC Danmark) were coated with $5 \mu \mathrm{g} / \mathrm{ml}$ of purified antigens in bicarbonate coating buffer ( $\mathrm{pH}$ 9.7) and incubated overnight at $4^{\circ} \mathrm{C}$. They were then washed and blocked with $3 \%$ non-fat dry milk in Tween-20 Tris buffer solution (TBST) for $2 \mathrm{~h}$ at $37^{\circ} \mathrm{C}$. After washing of the wells, primary sera from experimental and control mice were added in duplicate at the indicated dilutions. After incubation $2 \mathrm{~h}$ at $37^{\circ} \mathrm{C}$ and washing, HRP-conjugated anti-mouse IgG (Santa Cruz Biotech, USA) was added. Plates were incubated for $1 \mathrm{~h}$ at $37^{\circ} \mathrm{C}$, washed, and freshly prepared TMB substrate solution (tetramethyl benzidine in $0.05 \mathrm{M}$ phosphatecitrate buffer, $\mathrm{pH}$ 5.0; Sigma) was added to develop reaction. Reaction was stopped by adding $2 \mathrm{M}$ sulfuric acid, then was analyzed spectrophotometrically at $450 \mathrm{~nm}$.

Antibody isotyping (Ghochikyan et al., 2003). To determine the specific isotypes, sera from individual mice were diluted $1: 2000$ and tested in duplicate as described above. To detect mouse IgG1, IgG2a, IgG2b or IgM isotypes, we used anti-mouse Ig-subclassspecific HRP-conjugated secondary antibodies (Gifted by Dr. Xuesong Liu).

Preparation of membrane extracts (DiMartino et al., 2001). Human renal tissue was homogenized on ice in homogenate solution $(50 \mathrm{mmol} / \mathrm{L}$ Tris- $\mathrm{HCl} \mathrm{pH} 7.2,250 \mathrm{mmol} / \mathrm{L}$ sucrose, $50 \mathrm{mmol} / \mathrm{L}$ $\mathrm{MgCl}_{2}, 2.5 \mathrm{mmol} / \mathrm{L}$ EDTA, $2.5 \mathrm{mmol} / \mathrm{L}$ leupeptin, $0.5 \mathrm{mmol} / \mathrm{L}$ PMSF, $1 \mathrm{mmol} / \mathrm{L}$ pefabloc). The homogenate was centrifuged at $1,500 \mathrm{~g}$ for 5 minutes at $4^{\circ} \mathrm{C}$. Supernatant were collected and the precipitate was resuspended by homogenate solution, homogenated 
and centrifuged at $1,500 \mathrm{~g}$ for 5 minutes at $4^{\circ} \mathrm{C}$. Supernatant were collected again. Total supernatant was mixtured and centrifuged at $7,500 \mathrm{~g}$ for 10 minutes at $4^{\circ} \mathrm{C}$. Supernatant were collected and centrifuged at $100,000 \mathrm{~g}$ for 35 minutes at $4^{\circ} \mathrm{C}$. Precipitate was collected and resuspended in $150 \mu \mathrm{l}$ buffer $(7 \mathrm{~mol} / \mathrm{L}$ urea, $2 \mathrm{~mol} / \mathrm{L}$ thiorea, $1 \%$ TritonX-100, $50 \mathrm{~mol} / \mathrm{L}$ DTT, $0.4 \%$ carrier ampholytes $\mathrm{pH} 3-10)$. Store at $-20^{\circ} \mathrm{C}$.

A deglycosylation of crude membrane fraction was performed as follows (Hosoyamada et al., 2004): Denature $100 \mu \mathrm{g}$ of crude membrane fraction in $1 \times$ Glycoprotein Denature Buffer at $100^{\circ} \mathrm{C}$ for 30 minutes. The denatured protein was deglycosylated with 1,000 U PNGase F containing 10\% NP-40 (New England BioLabs) at $37^{\circ} \mathrm{C}$ overnight.

Western blot analysis. Western blot analysis was performed as follows (Hosoyamada et al., 2004; Sekine, Watanabe and Gilkeson, 2004): $40 \mu \mathrm{g}$ of the sample was separated with $10 \%$ polyacrylamide gel by Laemmli method and blotted on a nitrocellulose filter (Millipore Corp). The blotted filter was blocked overnight at $4^{\circ} \mathrm{C}$ in blocking solution $(1 \times \mathrm{TBS}$ with $5 \%$ non-fat milk and $0.02 \%$ Tween $20)$. The blocked filter was shaken for 4 hours at room temperature using mouse anti-hURAT1, hOAT1 or hOAT3 antibodies $(1: 3000)$ with or without $100 \mu \mathrm{g} / \mathrm{ml}$ antigen fragments in the TBST solution containing $1 \%$ bovine serum albumin. After washed three times with TBST, the filter was shaken for 45 minutes at room temperature with horseradish peroxidase-conjugated goat anti-mouse IgG ( $1: 2000$, Santa Cruz Biotech), and then washed three times with TBST. The detection was performed according to the manufacturer's instructions with the ECL kit (Santa Cruz Biotech).

Immunohistochemistry. Immunohistochemistry was performed as described (Hyink et al., 2001). Human sliced kidney was embedded in paraffin. The $2 \mu \mathrm{m}$ sections were stained with mouse antihURAT1, hOAT1 or hOAT3 antibodies $(1: 200)$ overnight at $4^{\circ} \mathrm{C}$, and were washed 3 times with PBS followed by staining with biotin-conjugated goat anti-mouse IgG for 30 minutes at $37^{\circ} \mathrm{C}$, then washed 3 times with PBS and stained with horseradish peroxidaseconjugated streptavidin for 30 minutes at $37^{\circ} \mathrm{C}$. After washed 3 times with PBS, the sections were stained with DAB as described. Nuclei were stained with hematoxylin. Images were visualized on an Olympus BH-2 microscope.

Immunofluorescence of hURAT1 Expressed in Xenopus Oocyte (Enomoto et al., 2002; Hosoyamada et al., 2004). Plasmid pCR2.1hURAT1 which containing hURAT1 full length cDNA and T7 promoter was linearized and synthesized into cRNA by mMESSAGE mMACHINE High Rield RNA Transcription Kit (Ambion). Xenopus oocytes, which were injected with $50 \mathrm{ng}$ of hURAT1 full length cRNA and cultured for $3 \mathrm{~d}$ at $18^{\circ} \mathrm{C}$, were fixed in $4 \%$ paraformaldehyde in ND96 $(96 \mathrm{mM} \mathrm{NaCl}, 2.0 \mathrm{mM} \mathrm{KCl}, 1.8 \mathrm{mM}$ $\mathrm{CaCl}_{2}, 1.0 \mathrm{mM} \mathrm{MgCl} 2,5.0 \mathrm{mM}$ HEPES, $\mathrm{pH} 7.4$ ) overnight at $4^{\circ} \mathrm{C}$. Eight $\mu \mathrm{m}$-frozen sections were made by a Cryostat (Thermo Shandon) and dried by cool air for $30 \mathrm{~min}$. The sections were stained with mouse anti-hURAT1 polyclonal antibody generated by genetic immunization, followed by staining with rhodamine-conjugated goat anti-mouse $\operatorname{IgG}(1: 200$, Santa Cruz Biotech). Images were visualized by a confocal laser microscope (Lasersharp2000; BioRad).

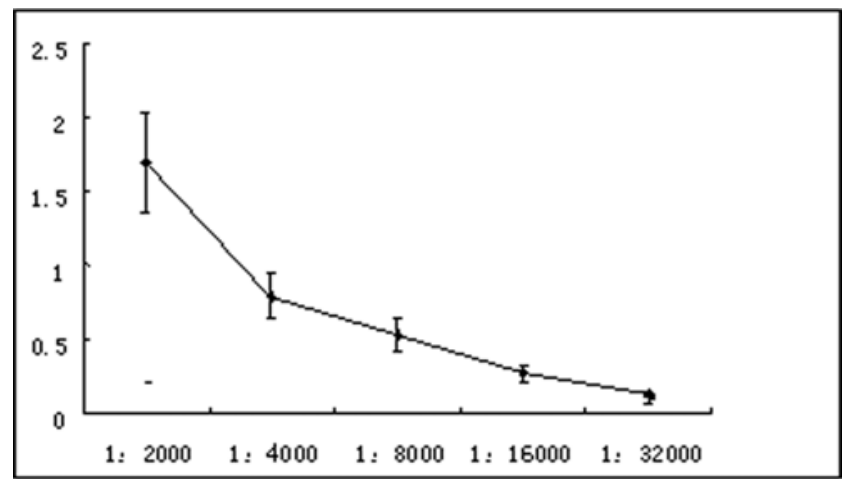

Fig. 1. Titer of anti-hURAT1 antibody detected in the sera of mice induced by genetic immunization $(n=5)$.

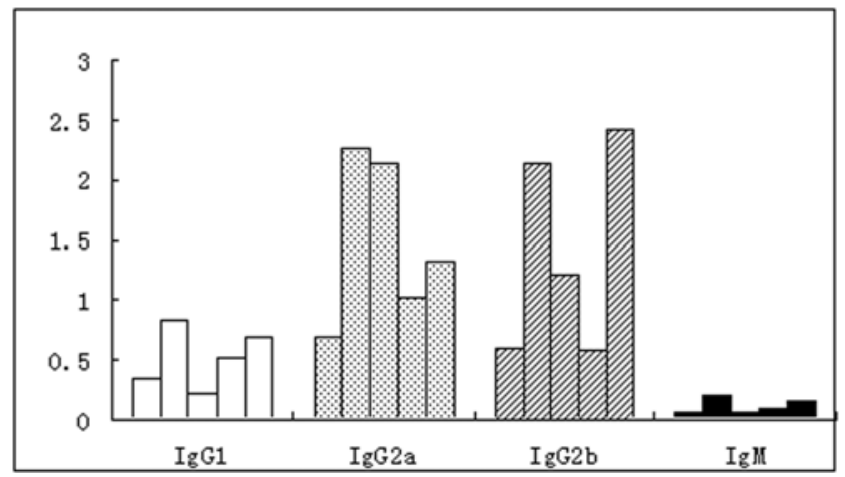

Fig. 2. Isotyping of anti-hURAT1 antibody after genetic immunization. Each serum from five mice was diluted $1: 2000$ and used for detection of $\operatorname{IgG} 1, \operatorname{IgG} 2 \mathrm{a}$, IgG2b and IgM subclasses of anti-hURAT1 antibody. The titers of $\operatorname{IgG} 2 \mathrm{a}$ and IgG2b detected were higher than IgG1 subclass antibody, while the antibody of IgM subclass was hardly detected.

\section{Results}

Generation of antibodies by genetic immunization. All mice immunized with the various plasmids coated with microscopic gold particles using the Helios gene gun induced high level antibodies against hURAT1, hOAT1, and hOAT3, respectively. The titer of antibody against hURAT1 was detected in two separate experiments by ELISA and were equal to $1: 32,000$ (Fig. 1). Results of antibodies against hOAT1 and hOAT3 showed similar titers compared with antibody against hURAT1 (data not shown). To verify efficiency of this genetic immunization system, we immunized mice with empty plasmid pBQAP-TT plus two adjuvant plasmids pCMV-GM-CSF and pCMV-Flt3L as controls. And mice immunized with these vectors did not induce any antibody production (data not shown).

Characterization of antibodies by isotyping. We analyzed isotypes of anti-hURAT1 antibodies in the sera of five mice and found that all animals generated $\operatorname{IgG} 2 \mathrm{a}$ and $2 \mathrm{~b}$ antibodies, whereas the level of IgG1 was very low. There was no IgM antibody production detected in immunized mice (Fig. 2). 


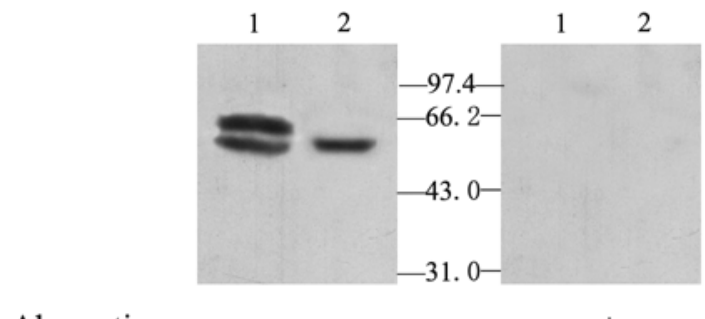

Absorption

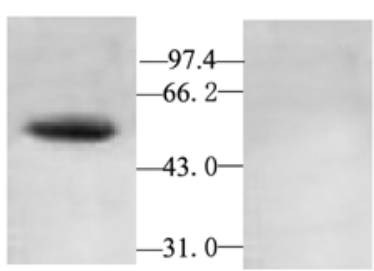

$+$

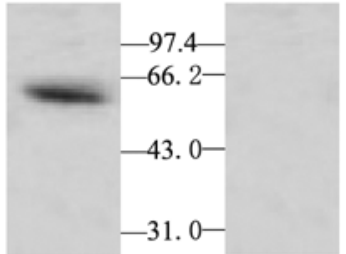

$+$

Fig. 3. Western blot analysis of membrane protein prepared from human kidney. (A) With mouse anti-hURAT1 antibody. Lane 1, crude membrane fraction of human kidney. Lane 2, a memebrane fraction sample deglycosylated by PNGase F (B) With mouse antihOATlantibody. (C) With mouse anti-hOAT3 antibody. The absorption tests were performed by preincubation of the antigen fragments $(100 \mu \mathrm{g} / \mathrm{ml})$ with their corresponding antibodies.

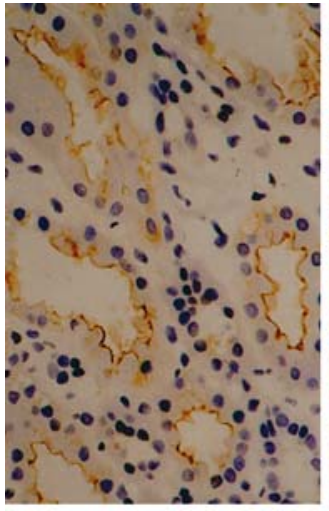

(A)

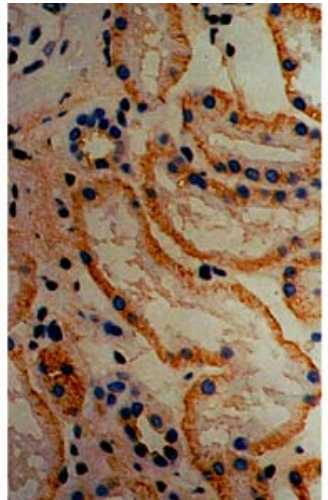

(B)

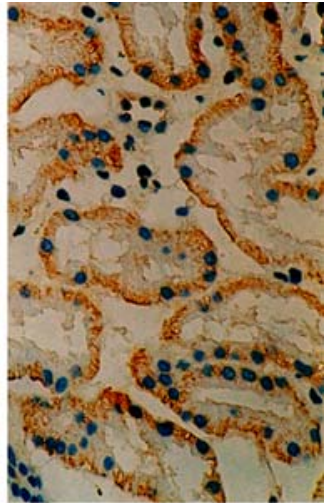

(C)

Fig. 4. Immunohistochemical detection of hURAT1, hOAT1 and hOAT3 in human kidney. The hURAT1 was restricted to the brush border membrane of the proximal tubule cells (A); The hOAT1 (B) and hOAT3 (C) were located in the basolateral membrane of proximal tubular cells. Magnifications. $\times 400$.

\begin{abstract}
Antibodies recognition to native proteins of human kidney membrane extracts. To identify antibodies' specificity, we isolated membrane extracts from human kidney and detected native proteins by Western blot analysis. Antibody against hURAT1 recognized two bands of $58 \mathrm{kD}$ and $64 \mathrm{kD}$ protein. The upper $64 \mathrm{kD}$ band relocated to the lower $58 \mathrm{kD}$ band following deglycosylation of crude membrane fraction using PNGase F (lane 3A). Therefore, the $58 \mathrm{kD}$ band corresponds to hURAT1 native protein, while the $64 \mathrm{kD}$ band is a glycosylated form of hURAT1. Antibodies against hOAT1 and hOAT3 recognized the bands of $55 \mathrm{kD}$ and $57 \mathrm{kD}$ proteins, respectively. These results were consistent with previous reports (Hosoyamada et al., 1999; Cha et al., 2001; Hosoyamada et al., 2004). These bands completely disappeared following the addition of $100 \mu \mathrm{g} / \mathrm{ml}$ of corresponding antigen expressed in E. coli BL21 (Fig. 3).

The antibodies' specificity was further identified by immunohistochemistry on human sliced kidney tissues. Immunohistochemistry results indicated that hURAT1 was prominent in the luminal membrane of proximal tubules, while hOAT1
\end{abstract}

and hOAT3 were located in the basolateral membrane of proximal tubular cells (Fig. 4). These results were also consistent with several recent reports (Hosoyamada et al., 1999; Cha et al., 2001; Enomoto et al., 2002; Kojima et al., 2002).

Antibody's recognition to hURAT1 expressed in Xenopus Oocyte. To examine the capability of antibodies to recognize expressed proteins in vitro, full-length cDNA of hURAT1 was cloned into plasmid pCR2.1 and the cRNA was synthesized in vitro by mMESSAGE mMACHINE ${ }^{\mathrm{TM}}$ Kit (Ambion), then was injected into Xenopus oocyte. The targeting of hURAT1 protein was evaluated by mouse anti-hURAT1 polyclonal antibody generated by genetic immunization. Significant red fluorescence was readily observed at the oocytes periphery (Fig. 5), demonstrating that mouse anti-hURAT1 polyclonal antibody could recognize hURAT1 protein targeted to oocyte plasma membranes. These results suggest that our antibodies generated by genetic immunization not only recognized native proteins, but also recognized expressed protein in vitro. 


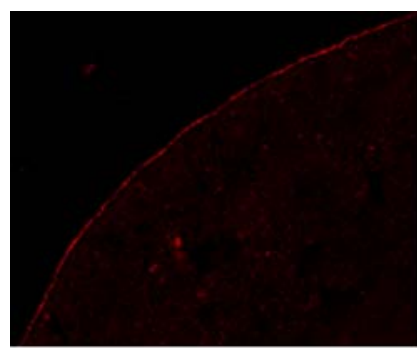

(A)

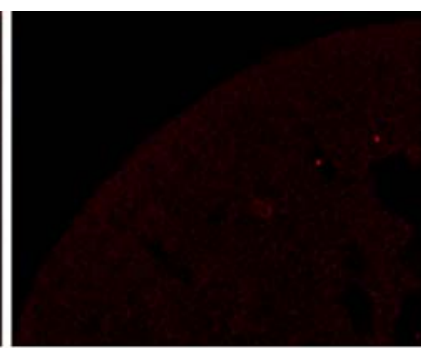

(B)
Fig. 5. Immunofluorescence of hURAT1 cRNA-injected oocyte using mouse anti-hURAT1 antibody. The significant red fluorescence was readily observed at the periphery of oocytes having been microinjected with the hURAT1 cRNA (A), while no fluorescence was detected at the periphery of oocytes having been microinjected with water (B).

\section{Discussion}

The present study clearly demonstrated that we have generated three specific antibodies against human URAT1, OAT1 and OAT3, using a set of improved genetic immunization system. UA can be tremendously beneficial because it can scavenge potentially harmful reactive oxygen species, contributing to longevity in certain vertebrates (Hediger, 2002). However, too much UA can also cause significant health problems, such as kidney stones and gout. Furthermore, increased blood UA is an independent risk factor for cardiovascular and renal diseases (Verdecchia et al., 2000; Alderman, 2001; Nakagawa et al., 2003; Iseki et al., 2004; Feig, 2005; Sanchez-Lozada et al., 2005; Short, Tuttle, 2005; $\mathrm{Wu}$ et al., 2005). UA excretion is mainly performed by kidney, and approximately two thirds of the daily turnover of UA is accounted by urinary excretion (Hediger, 2002; Rafey et al., 2003). The three UA transporters expressed on human renal proximal tubule cells mentioned above are more likely to play central roles in UA excretion. Antibodies against these transporters will help us to identify the molecular basis of UA transport in physiological and pathological conditions.

To generate an antibody against a foreign protein usually requires purification of that protein, which is then injected into an animal. The isolation of enough pure protein is timeconsuming and sometimes difficult. Genetic immunizationbased antibody production offers several advantages, including high specificity, simplicity and low cost (Chambers, Johnston, 2003). But it induces limited immune response frequently (Babiuk, van, Babiuk, 1999). To enhance immune response and antibodies' specificity, Chambers RS and Johnston S (Chambers and Johnston, 2003) developed a set of improved genetic immunization system. This new system contains a plasmid pBQAP-TT which was used to insert antigen gene, and two adjuvant plasmids, pCMVi-GMCSF and pCMViFlt3L. The pBQAP-TT encode a secretion leader sequence from the highly expressed human gene encoding $\alpha 1$-antitrypsin (AAT), an exogenous T-cell epitopes (P2 and p30) and flanking regions from tetanus toxin, and a highly soluble and stably folded domain from the rat cartilage oligomerization matrix protein (COMP). These sequences can enhance antigen uptake by antigen-presenting cells or allow $\mathrm{T}$ helperindependent B-cell activation, block poorly folded or insoluble antigen, therefore markedly increase the antibody response. The pCMVi-GMCSF and the pCMVi-Flt3L contain mouse granulocyte/macrophage colony-stimulating factor (GM-CSF) and FMS-like tyrosine kinase 3 ligand (Flt3L) respectively. These two factors are potent growth factors for dendritic cells. With this antibody production system, many antibodies of high throughput and high specificity were produced (Chambers, Johnston, 2003). To address whether the antibodies against membrane proteins can be induced by this improved system, we selected the antigen fragments with high antigenicity of hURAT1, hOAT1 and hOAT3, and immunized NIH mice with this system by gene gun. After four times of immunization, we collected a high-level antibody against these membrane proteins. ELISA measurements showed that the antibodies had a high titer of $1: 32000$. These serum antibodies levels are much higher than those of many reports on DNA immunization (Ghochikyan et al., 2003; Wang et al., 2005; Zheng et al., 2005).

We then analyzed antibodies isotypes and found that the $\operatorname{IgG} 2 \mathrm{a}$ and $2 \mathrm{~b}$ antibodies were predominately generated by this DNA immunization method whereas the level of IgG1 was low. There was no IgM antibody production detected in immunized mice. These results were not consistent with a previous report in which only the IgG1 isotype was induced in $\mathrm{BALB} / \mathrm{c}$ mice with this genetic immunization system (Chambers, Johnston, 2003). This difference may be due to the fact that we used NIH instead of BALB/c mice.

To examine whether the antibodies we produced were useful in measuring the natural antigens, we first identified them by Western blot, and found that in human renal membrane extracts, the antibodies could recognize the specific protein bands in consistence with the expected molecular weight from the amino acid sequence of hURAT1, hOAT1 and hOAT3, respectively. And these bands completely disappeared following the addition of $100 \mu \mathrm{g} / \mathrm{ml}$ of purificated antigens of hURAT1, hOAT1 and hOAT3 respectively. Immunohistochemistry of human kidney sections showed that staining of hURAT1 was restricted to the brush border membrane of the proximal tubule cells, while hOAT1 and hOAT3 were located in the basolateral membrane of proximal tubular cells. These results demonstrated that our antibodies have high specificity and can recognize the native proteins of hURAT1, hOAT1 and hOAT3, respectively.

To examine whether these antibodies can recognize the expressed products in vitro, full-length cRNA of hURAT1 was injected into Xenopus oocyte and the fluorescence was observed by confocal laser microscope. The result showed that significant red fluorescence was readily observed at the oocytes periphery when oocytes were microinjected with an hURAT1 cRNA, while no fluorescence was detected at 
oocytes membrane when microinjected with water. This study demonstrated that the antibody can also recognize the expressed protein of hURAT1 in vitro.

Collectively, we have, for the first time, generated highlevel and high-specificity antibodies against hURAT1, hOAT1 and hOAT3 with the method of genetic immunization, providing an important tool for studying UA transporters and for producing antibodies against other cell membrane transporters.

Acknowledgments We are grateful to Dr. Ross Chambers for kindly providing the pBQAP-TT, pCMVi-GMCSF and pCMVi-Flt3L plasmids, Dr. Xuesong Liu for providing antimouse Ig-subclass-specific HRP-conjugated secondary antibodies. This work was supported by grants from the National Natural Science Foundation of China (No. 30100062), from the Creative Research Group Fund of the National Foundation Committee of Natural Science of P.R. China (30121005), and from the Main State Basic Research Development Program of P.R. China (2007CB507400).

\section{References}

Alderman, M. H. (2001) Serum uric acid as a cardiovascular risk factor for heart disease. Curr. Hypertens. Rep. 3, 184-189.

Babiuk, L. A., van Drunen, Littel-van den Hurk and Babiuk, S. L. (1999) Immunization of animals: from DNA to the dinner plate. Vet. Immunol. Immunopathol. 72, 189-202.

Baca-Estrada, M. E., Ewen, C., Mahony, D., Babiuk, L. A., Wilkie, D. and Foldvari, M. (2002) The haemopoietic growth factor, Flt3L, alters the immune response induced by transcutaneous immunization. Immunology 107, 69-76.

Barouch, D. H., Letvin, N. L. and Seder, R. A. (2004) The role of cytokine DNAs as vaccine adjuvants for optimizing cellular immune responses. Immunol. Rev. 202, 266-274.

Capasso, G., Jaeger, P., Robertson, W. G. and Unwin, R. J. (2005) Uric acid and the kidney: urate transport, stone disease and progressive renal failure. Curr. Pharm. Des. 11, 4153-4159.

Cha, S. H., Sekine, T., Fukushima, J. I., Kanai, Y., Kobayashi, Y., Goya, T. and Endou, H. (2001) Identification and characterization of human organic anion transporter 3 expressing predominantly in the kidney. Mol. Pharmacol. 59, 1277-1286.

Chambers, R. S. and Johnston, S. A. (2003) High-level generation of polyclonal antibodies by genetic immunization. Nat. Biotechnol. 21, 1088-1092.

Cribbs, D. H., Ghochikyan, A., Vasilevko, V., Tran, M., Petrushina, I., Sadzikava, N., Babikyan, D., Kesslak, P., Kieber-Emmons, T., Cotman, C. W. and Agadjanyan, M. G. (2003) Adjuvantdependent modulation of Th1 and Th2 responses to immunization with beta-amyloid. Int. Immunol. 15, 505-514.

DiMartino, S. J., Shah, A. B., Trujillo, G. and Kew, R. R. (2001) Elastase controls the binding of the vitamin D-binding protein (Gc-globulin) to neutrophils: a potential role in the regulation of C5a co-chemotactic activity. J. Immunol. 166, 2688-2694.

Enomoto, A., Kimura, H., Chairoungdua, A., Shigeta, Y., Jutabha, P., Cha, S. H., Hosoyamada, M., Takeda, M., Sekine, T., Igarashi, T., Matsuo, H., Kikuchi, Y., Oda, T., Ichida, K.,
Hosoya, T., Shimokata, K., Niwa, T., Kanai, Y. and Endou, H. (2002) Molecular identification of a renal urate anion exchanger that regulates blood urate levels. Nature 417, 447452.

Feig, D, I. (2005) Uric acid and hypertension in adolescents. Semin. Nephrol. 25, 32-38.

Ghochikyan, A., Vasilevko, V., Petrushina, I, Movsesyan, N., Babikyan, D., Tian, W., Sadzikava, N., Ross, T. M., Head, E., Cribbs, D. H. and Agadjanyan, M. G. (2003) Generation and characterization of the humoral immune response to DNA immunization with a chimeric beta-amyloid-interleukin-4 minigene. Eur. J. Immunol. 33, 3232-3241.

Hediger, M. A. (2002) Kidney function: gateway to a long life? Nature 417, 393-395.

Hediger, M. A., Johnson, R. J., Miyazaki, H. and Endou, H. (2005) Molecular physiology of urate transport. Physiology (Bethesda) 20, 125-133.

Hosoyamada, M., Ichida, K., Enomoto, A., Hosoya, T. and Endou, H. (2004) Function and localization of urate transporter 1 in mouse kidney. J. Am. Soc. Nephrol. 15, 261-268.

Hosoyamada, M., Sekine, T., Kanai, Y. and Endou, H. (1999) Molecular cloning and functional expression of a multispecific organic anion transporter from human kidney. Am. J. Physiol. 276, 122-128.

Hyink, D. P., Rappoport, J. Z., Wilson, P. D. and Abramson, R. G. (2001) Expression of the urate transporter/channel is developmentally regulated in human kidneys. Am. J. Physiol. Renal. Physiol. 281, 875-886.

Iseki, K., Ikemiya, Y., Inoue, T., Iseki, C., Kinjo, K. and Takishita, S. (2004) Significance of hyperuricemia as a risk factor for developing ESRD in a screened cohort. Am. J. Kidney Dis. 44, 642-650.

Kodadek, T. (2001) Protein microarrays: prospects and problems. Chem. Biol. 8, 105-115.

Kojima, R., Sekine, T., Kawachi, M., Cha, S. H., Suzuki, Y. and Endou, H. (2002) Immunolocalization of multispecific organic anion transporters, OAT1, OAT2, and OAT3, in rat kidney. $J$. Am. Soc. Nephrol. 13, 848-857.

Lang, F., Greger, R. and Deetjen, P. (1972) Handling of uric acid by the rat kidney. II. Microperfusion studies on bidirectional transport of uric acid in the proximal tubule. Pflugers Arch. 335, 257-265.

Mount, D. B. (2005) Molecular physiology and the fourcomponent model of renal urate transport. Curr. Opin. Nephrol. Hypertens. 14, 460-463.

Nakagawa, T., Mazzali, M., Kang, D. H., Kanellis, J., Watanabe, S., Sanchez-Lozada, L. G., Rodriguez-Iturbe, B., HerreraAcosta, J. and Johnson, R. J. (2003) Hyperuricemia causes glomerular hypertrophy in the rat. Am. J. Nephrol. 23, 2-7.

Rafey, M. A., Lipkowitz, M. S., Leal-Pinto, E. and Abramson, R. G. (2003) Uric acid transport. Curr. Opin. Nephrol. Hypertens. 12, 511-516.

Sanchez-Lozada, L. G., Tapia, E., Santamaria, J., Avila-Casado, C., Soto, V., Nepomuceno, T., Rodriguez-Iturbe, B., Johnson, R. J. and Herrera-Acosta, J. (2005) Mild hyperuricemia induces vasoconstriction and maintains glomerular hypertension in normal and remnant kidney rats. Kidney Int. 67, 237-247.

Schali, C. and Roch-Ramel, F. (1981) Uptake of [3H]PAH and [14C]urate into isolated proximal tubular segments of the pig kidney. Am. J. Physiol. 241, 591-596. 
Sekine, H., Watanabe, H. and Gilkeson, G. S. (2004) Enrichment of anti-glomerular antigen antibody-producing cells in the kidneys of MRL/MpJ-Fas(lpr) mice. J. Immunol. 172, 39133921.

Short, R. A. and Tuttle, K. R. (2005) Clinical evidence for the influence of uric acid on hypertension, cardiovascular disease, and kidney disease: a statistical modeling perspective. Semin. Nephrol. 25, 25-31.

Sun, W., Hu, Y., Gong, J., Zhu, C. and Zhu, B. (2005) Identification of beta-lactamase inhibitory peptide using yeast two-hybrid system. Biochemistry (Mosc) 70, 753-760.

Tang, D. C., DeVit, M. and Johnston, S. A. (1992) Genetic immunization is a simple method for eliciting an immune response. Nature 356, 152-154.

Trinchieri, G. (1998) Immunobiology of interleukin-12. Immunol. Res. 17, 269-278.

Verdecchia, P., Schillaci, G., Reboldi, G., Santeusanio, F.,
Porcellati, C. and Brunetti, P. (2000) Relation between serum uric acid and risk of cardiovascular disease in essential hypertension. The PIUMA study. Hypertension 36, 1072-1078.

Wang, Z., Yuan, Z., Matsumoto, M., Hengge, U. R. and Chang, Y. F. (2005) Immune responses with DNA vaccines encoded different gene fragments of severe acute respiratory syndrome coronavirus in BALB/c mice. Biochem. Biophys. Res. Commun. 327, 130-135.

Wu, J., Chen, X., Xie, Y., Yamanaka, N., Shi, S., Wu, D., Liu, S. and Cai, G. (2005) Characteristics and risk factors of intrarenal arterial lesions in patients with IgA nephropathy. Nephrol. Dial Transplant 20, 719-727.

Zheng, L. Y., Mou, L., Lin, S., Lu, R. M. and Luo, E. J. (2005) Enhancing DNA vaccine potency against hantavirus by coadministration of interleukin-12 expression vector as a genetic adjuvant. Chin. Med. J. (Engl) 118, 313-319. 